\title{
A FRATERNIDADE COMO ELEMENTO FUNDAMENTAL PARA A DISSEMINAÇÃO E O ALCANCE DOS OBJETIVOS GLOBAIS DA ONU EM TEMPOS DE PANDEMIA: UM OLHAR NA PERSPECTIVA DO IDOSO
}

\author{
Roberta Terezinha Uvo Bodnar ${ }^{1}$ \\ Zenildo Bodnar ${ }^{2}$
}

DOI: https://doi.org/10.47306/978-65-88213-03-2.133-148

Sumário: 1 Introdução; 2 A ONU e a proteção do Idoso frente aos Objetivos Globais em tempos de Pandemia: um desafio a ser cumprido; 3 O Idoso no contexto dos novos padrões de interação: a participação social e seu papel transformador; 4 A Fraternidade e os Objetivos Globais em tempos de Pandemia: o reconhecimento da agenda em prol do Idoso - por um novo e urgente modelo relacional; 5 Considerações finais; 6 Referências.

\section{Introdução}

A preocupação com o número de $\operatorname{Idosos}^{3}$ no Mundo $^{4}$ é questão que vem sendo tratada há três décadas pela Organização das Nações Unidas (ONU), desde a primeira Assembleia Mundial sobre o Envelhecimento em 1982. O aumento significativo dessa estatística representa

\footnotetext{
${ }^{1}$ Doutoranda em Ciência Jurídica na Universidade do Vale do Itajaí (UNIVALI) em dupla titulação com Widener University Delaware Law School (EUA). Mestre em Direito pela Universidade Federal de Santa Catarina (UFSC). Procuradora Federal (AGU). E-mail: roberta.uvo@gmail.com

${ }^{2}$ Doutor em Direito e Doutor em Ciências Humanas pela Universidade Federal de Santa Catarina (UFSC). Docente do Programa de Pós-Graduação em Ciência Jurídica da Universidade do Vale do Itajaí (UNIVALI). Registrador de Imóveis. E-mail: zenildo.bodnar1@gmail.com

${ }^{3}$ Adota-se o conceito cronológico de Idoso, previsto no Estatuto do Idoso, qual seja: "pessoa com idade igual ou superior a 60 (sessenta) anos". BRASIL. Lei n. 10.741, de $1^{\circ}$ de outubro de 2003. Dispõe sobre Estatuto do Idoso e dá outras providências. Disponível em: planalto.gov.br/ccivil_03/leis/2003/110.741.htm. Acesso em: 28 abr. 2020.

${ }^{4}$ De acordo com a World Health Organization (WHO): “The pace of population ageing around the world is also increasing dramatically. France had almost 150 years to adapt to a change from $10 \%$ to $20 \%$ in the proportion of the population that was older than 60 years .However, places such as Brazil, China and India will have slightly more than 20 years to make the same adaptation" [O ritmo do envelhecimento da população em todo o mundo também está aumentando drasticamente. A França teve quase 150 anos para se adaptar a uma mudança de $10 \%$ para $20 \%$ na proporção da população com mais de 60 anos. No entanto, lugares como Brasil, China e Índia terão um pouco mais de 20 anos para fazer a mesmo adaptação.] (Tradução livre). WORLD HEALTH ORGANIZATION. Ageing and health. 5 feb. 2018. Disponível em: who.int/news-room/fact-sheets/detail/ageingand-health. Acesso em: 29 abr. 2020.
} 
a assunção de várias questões com ela relacionadas, inclusive na área dos Direitos, com destaque aos Direitos Sociais ${ }^{5}$.

Uma breve análise dos temas pertinentes aos Direitos do Idoso perante à ONU, são suficientes para comprovar que a referida Instituição está de fato preocupada com os reflexos em decorrência do aumento progressivo do número de Idosos, inclusive com o modo de agir da Família, da Sociedade e do Estado como entes responsáveis por esse segmento.

No Brasil essa preocupação, também, está presente, não só na Constituição da República Federativa do Brasil de 1988 (CRFB/1988), como no Estatuto do Idoso (BRASIL, 2020), nas decisões dos Tribunais, assim como no desenvolvimento de uma corrente que examina esse assunto sob o prisma do Direito e da Fraternidade.

Há, ainda, um aspecto que guarda relevância com a temática proposta, cuja referência diz respeito à participação social. O fundamento da referida indicação condiz com os movimentos sociais, dentro do qual há de se situar, segundo um quadro de referência da ação social, a categoria do Idoso. No âmbito desta pesquisa, a temática constitui um ponto essencial de análise por usufruir da condição de elemento fundante - ainda que não único - de uma das formas de participação, de padrão e de interação nos espaços públicos e privados.

Com efeito, o presente estudo, além de expor a caracterização do Idoso, tem como pressuposto apresentar a Fraternidade como elemento fundamental para a disseminação e o alcance dos Objetivos Globais (ONU), tendo como cenário o contexto dos novos padrões de interação e a possibilidade de uma agenda nos planos internacional e nacional dirigida ao Idoso, tão mais em tempos de Pandemia.

\footnotetext{
${ }^{5}$ Considera-se Direitos Sociais "um todo [...] integrantes daquele corpus: um mínimo existencial (ou direito a um mínimo para uma existência condigna); um direito à saúde (ou à proteç̧ão da saúde); um direito à habitação (ou a habitação condigna); um direito à segurança social (ou à assistência social); um direito ao trabalho e um dirieto ao ensino (à educação ou à formação)", segundo Jorge Reis Novais. NOVAIS, Jorge Reis. Direitos Sociais Teoria jurídica dos direitos sociais enquanto direitos fundamentais. 2 ed. Lisboa: AAFDL, 2017. p. 50-51.

6 "A major global demographic trend is population ageing. As the WHO notes, " $[\mathrm{f}]$ or the first time in history, most people can expect to live into their $60 \mathrm{~s}$ and beyond. The consequences for health, health systems, their workforce and budgets are profound' (WHO, 2015a). The global population continues to age. Nevertheless, the extent and nature of ageing is uneven. Moreover, the extra years of life gained are not all lived in good health. At the same time, the nature of the health challenges facing social security systems is changing." "[Uma das principais tendências demográficas globais é o envelhecimento da população. Como a OMS observa, "[f] ou pela primeira vez na história, a maioria das pessoas pode esperar viver em seus 60 anos e além. As consequências para a saúde, sistemas de saúde, sua força de trabalho e orçamentos são profundos.' (OMS, 2015a). A população global continua a envelhecer. No entanto, a extensão e a natureza do envelhecimento são desiguais. Além disso, os anos extras de vida adquirida não são todos vividos em boa saúde. Ao mesmo tempo, a natureza dos desafios de saúde que os sistemas de seguridade social estão mudando.]" (Tradução livre) INTERNATIONAL SOCIAL SECURITY ASSOCIATION. Megatrends and social security: demographic changes. Geneva, 2017. Disponível em: issa.int/en/details?uuid=1438fdf2-cd99-4b0a-bb13-8913b829db1d. Acesso em 22 jan. 2019. p. iv.
} 
Para atingir o objetivo firmado, utiliza-se como método de abordagem o dedutivo, e como método de procedimento o histórico, descritivo e argumentativo, como também a pesquisa bibliográfica.

Por fim, o estudo se encontra dividido em três partes fundamentais: $1^{\text {a }}$ ) apresenta-se a ONU e a proteção do Idoso frente aos Objetivos Globais em tempos de Pandemia, tendo-se como proposição o desafio que a temática confere e que resta por ser cumprido; $2^{\mathrm{a}}$ ) examinase a categoria do Idoso no contexto dos novos padrões de interação em face da participação social e seu papel transformador; e, $3^{\mathrm{a}}$ ) estabelece-se um paralelo entre as duas fontes de estudo, estudando as representações da Fraternidade e os Objetivos Globais em tempos de Pandemia e, para tanto, tem-se como foco, buscar no reconhecimento da agenda em prol do Idoso, um novo e urgente modelo de agir.

\section{A ONU e a proteção do Idoso frente aos Objetivos Globais em tempos de Pandemia: um desafio a ser cumprido}

A Organização das Nações Unidas (ONU) é uma organização internacional com atuação global, e de dimensão universal, formada por países que se reuniram voluntariamente a ocupar o centro da cooperação no mundo, de forma que, "as Nações Unidas se tornaram o principal fórum para abordar questões que transcendem as fronteiras nacionais e não podem ser resolvidas por nenhum país que atue sozinho". (ONU, 2020).

Dentre as atribuições da ONU, confere destaque a atenção ao envelhecimento populacional em prol dos Direitos do Idoso, o que tem sido levado a termo há três décadas. Como principais instrumentos pertinentes à temática do idoso, constantes da página oficial das Nações Unidas Brasil (2020), são apresentados: o Plano de Ação Internacional de Viena sobre o Envelhecimento (1982), o Princípio das Nações Unidas em favor das pessoas Idosas (1991) 7, a Proclamação do Envelhecimento (1992), o Plano Internacional (2002), elaborado pela II Assembleia Mundial do Envelhecimento. Além desses, os Objetivos Globais, como os Objetivos de Desenvolvimento Sustentável (ODS) ${ }^{8}$ firmaram valiosa contribuição na esfera dos Objetivos Globais que devem ser implementados até 2030.

\footnotetext{
${ }^{7}$ Os United Nations Principles for Older Persons foram recepcionados pela Resolução n. 46, de 16 de dezembro de 1991, da Assembleia Geral das Nações Unidas, na qual a ONU indicou os seguintes Princípios: independência (itens 1 a 6); participação (itens 1 a 9); assistência (itens 10 a 14); realização pessoal (itens 15 e 16); dignidade (itens 17 e 18). UNITED NATIONS. 46/91. Implementation of the International Plan of Action on Ageing and Related Activities. Disponível em: un.org/en/ga/search/view_doc.asp?symbol=A/RES/46/91. Acesso em: 29 abr. 2020.

${ }^{8}$ De acordo com a ONU, são 17 Objetivos de Desenvolvimento Sustentável, os quais "devem ser implementados por todos os países do mundo durante os próximos 15 anos, até 2030”. NAÇÕES UNIDAS BRASIL. Conheça os
} 
Apesar de os Objetivos de Desenvolvimento Sustentável (ODS), não versarem expressamente sobre os Direitos do Idoso, de sua análise detalhada, verifica-se que muitos tratam implicitamente da questão, conforme se depreende da página oficial da United Nations (UN, 2020): erradicação da pobreza (ODS1); fome zero (ODS2); água potável e saneamento (ODS6); redução das desigualdades (ODS10); paz, justiça e instituições eficazes (ODS16); e, especialmente, o Objetivo Global 3: saúde e bem-estar.

O Objetivo Global que versa sobre a "saúde e bem-estar" é o mais impactado neste momento, em decorrência da Pandemia instalada pela COVID-199 ${ }^{9}$, a qual tem como marcador considerável: a saúde dos $\operatorname{Idosos}{ }^{10}$, ou pelo menos, em face deles, os efeitos são mais devastadores, implicando, em percentual significativo de prestação e, inclusive, de fatalidade.

A título ilustrativo, extrai-se do País mais atingido pela COVID-19 e com maior número de mortes, no caso os Estados Unidos da América ${ }^{11}$, a estatística do Centers for Disease Control and Prevention (CDC), integrante do Departamento de Saúde e Serviços Humanos dos Estados Unidos da América (USA, 2020), revisada em 25 de junho de 2020, no seguinte sentido: 8 (oito)

novos 17 Objetivos de Desenvolvimento Sustentável da ONU. Disponível em: nacoesunidas.org/conheca-osnovos-17-objetivos-de-desenvolvimento-sustentavel-da-onu/. Acesso em 28 jun. 2020.

${ }^{9}$ Sobre a COVID-19, explica a Fundação Oswaldo Cruz (Fiocruz): "inicialmente chamada de 2019-n-CoV, a infecção provocada pelo novo coronavírus recebeu o nome oficial de covid-19, em 11 de fevereiro: um acrônimo do termo "doença por corona vírus" em inglês (corona virus deceased 2019)". BRASIL. Fundação Oswaldo Cruz. Covid-19: que vírus é esse? Disponível em: portal.fiocruz.br/noticia/covid-19-que-virus-e-esse. Acesso em: 07 jun. 2020.

${ }^{10}$ Segundo o Centers for Disease Control and Prevention (CDC), integrante do Departamento de Saúde e Serviços Humanos dos Estados Unidos da América, revisadas em 30 de abril de 2020: "See below for estimated percent of adults with confirmed COVID-19 reported in the U.S: Hospitalization $31-70 \%$ of adults 85 years old and older 31$59 \%$ of adults $65-84$ years old; Admission to intensive care $6-29 \%$ of adults 85 years old and older $11-31 \%$ of adults $65-84$ years old; Deaths $10-27 \%$ of adults 85 years old and older $4-11 \%$ of adults $65-84$ years old." "[Veja abaixo a porcentagem estimada de adultos com COVID-19 confirmado relatado nos EUA: Hospitalização 31-70\% dos adultos com 85 anos ou mais $31-59 \%$ dos adultos com 65 a 84 anos; Admissão em terapia intensiva $6-29 \%$ de adultos com 85 anos ou mais $11-31 \%$ de adultos com 65 a 84 anos; Mortes 10 a 27\% de adultos com 85 anos ou mais $4-11 \%$ de adultos com 65 a 84 anos.]" (Tradução livre). UNITED STATES OF AMERICA. Department of Health and Human Services. Centers for Disease Control and Prevention. Older Adults. Page last reviewed [última revisão da página]: April 30, 2020. Disponível em: cdc.gov/coronavirus/2019-ncov/need-extraprecautions/older-adults.html. Acesso em: 07 jun. 2020.

${ }^{11}$ Avaliação realizada em 28 de junho de 2020, com base nos dados oficiais do Centers for Disease Control and Prevention (CDC), integrante do Departamento de Saúde e Serviços Humanos dos Estados Unidos da América, que descreve o total de 2.504.175 casos confirmados da COVID-19 e de 125.484 mortes em decorrência dessa infecção, em 28 de junho de 2020. UNITED STATES OF AMERICA. Department of Health and Human Services. Centers for Disease Control and Prevention. Cases in the U.S. Disponível em: cdc.gov/coronavirus/2019ncov/cases-updates/cases-in-us.html. Acesso em: 28 jun. 2020. 
em cada 10 (dez) mortes reportadas nos Estados Unidos da América, em razão da COVID-19, ocorreram em adultos com 65 (sessenta e cinco) anos ou mais ${ }^{12}{ }^{13}$.

Nesse cenário, quando se toma em consideração a COVID-19 e a Pandemia decorrente, a questão central diz respeito ao pleno respeito do Direito à Saúde - tomado em acepção aos titulares de tais Direitos - em conjunto com os Direitos à Vida e à Integridade Pessoal, dos quais se extrai outro aspecto, qual seja, a acepção de medidas do Seguro Social, em particular para aqueles que vivem em situação de vulnerabilidade, ou mesmo para quem se encontra fora de cobertura médica, e até mesmo para o caso de necessitarem de atendimento médico e de hospitalização. Logo, esses Direitos, assegurados nos instrumentos internacionais, necessitam todos da mais plena proteção, promoção e defesa, incluindo a sua respectiva concretização.

Os altos números de ações judiciais no Brasil, conforme se constata diariamente e do processo instaurado pelo Tribunal de Contas da União ${ }^{14}$, já retratavam - antes mesmo da Pandemia instalada pela COVID-19 - a realidade da burocracia envolvendo a Judicialização da Seguridade Social (Saúde, Previdência e Assistência Social). Isto é, mesmo considerando que algumas não são viáveis, a grande parte, ao contrário, tem evidenciado a incapacidade do Estado em suprir a sua grande missão na área da saúde: garantia do acesso universal e igualitário (CRFB/1988, artigo 196).

Quando não possuem condições de arcar com tratamentos, medicamentos e outros, ou não tem conhecimento de pleitear judicialmente tal direito, o Idoso acaba adoecendo e com isso é usurpada a sua dignidade, além de afetar o seu bem-estar maior: a própria vida segue exposta. Logo, constata-se que haverá a necessidade de programas contínuos direcionados ao Idoso e além da Solidariedade Intergeracional, a promoção da Fraternidade por parte de todos: Família, Sociedade e Estado.

\footnotetext{
${ }^{12}$ Consta no original: "8 out of $\mathbf{1 0}$ COVID-19 deaths reported in the U.S. have been in adults 65 years old and older". (negrito do original) UNITED STATES OF AMERICA. Department of Health and Human Services. Centers for Disease Control and Prevention. Older Adults. Disponível em: cdc.gov/coronavirus/2019-ncov/needextra-precautions/older-adults.html. Acesso em: 28 jun. 2020.

${ }^{13}$ Diferentemente do Brasil, onde é considerada Idosa a pessoa com idade igual ou superior a 60 (sessenta) anos, nos Estados Unidos da América é considerada Idosa a pessoa com idade igual ou superior a 65 (sessenta e cinco) anos.

${ }^{14}$ A Judicialização da Seguridade Social (Saúde, Previdência Social e Assistência Social) é Tema de grande impacto financeiro e estrutural para o Estado, em especial no caso do Brasil. Tendo por base essa constatação, especificamente no caso de Previdência e da Assistência Social, o Tribunal de Contas da União instaurou o processo n. 022.354/2017-4, conforme já citada conclusão do Relatório de Levantamento, de 5 de dezembro de 2018. BRASIL. Tribunal de Contas da União. Processo n. 022.354/2017-4. Disponível em: //pesquisa.apps.tcu.gov.br/\#/documento/acordaocompleto/2235420174.PROC\%2520/PROC\%253A02235420174/DTRELEVANCIA\%2520desc\%252C\%2520N UMACORDAOINT\%2520desc/0/\%2520?uuid=10d01d40-8af0-11ea-a4ad-6fa42d9b5c96. Acesso em: 30 abr. 2020.
} 
O Idoso em razão de sua "peculiar condição física e fisiológica, demanda proteção, promoção e defesa por parte de todos, inclusive da ONU, a qual em uma posição horizontal, preocupada também com a mudança do perfil da população mundial, tem buscado (re)afirmar o direito à saúde do idoso". (BODNAR e PILATI, 2015, p. 130).

Portanto, o Idoso necessita de "voz" e de "vez", seja no nível de titularidade, de "permissão" Estatal e, sobretudo, de atuação mais efetiva, inclusive por parte da ONU. Para esta atuação convém: valer-se da respeitosa dimensão dos Direitos à Saúde, sobretudo, em tempos de Pandemia, exemplo da COVID-19, a qual assola a humanidade.

\section{O Idoso no contexto dos novos padrões de interação: a participação social e seu papel transformador}

Há variados modos para examinar a categoria do Idoso. Na esfera conceitual, e/ou em uma matriz processual ou de gestão, persistem várias dimensões para recepcionar a temática. Há ainda uma outra, a que se volta para uma "lista das capacidades, derivadas do conceito de uma vida de acordo com a dignidade humana", conforme apontada por Nussbaum (2013, p. 343) e que, encontra-se "formulada e justificada do que qualquer determinação particular dos deveres correspondentes".

Assim, são três as perspectivas relativas ao Idoso e sua participação social e seu papel transformador, as quais convém sejam enumeradas: i) uma, de matriz conceitual; ii) duas, atinente à ordem processual; e, por último, iii) uma terceira, relativa à capacidade, cuja exigência central está no centro de uma vida com dignidade, conforme lição de Nussbaum.

Inicialmente, lança-se mão de apresentar algumas concepções a respeito da dimensão conceitual e, para tanto, parte-se do significado da expressão "Idoso".

É fato que há muitos termos nesse sentido, tais como, a própria denominação "idoso", como "velho", "velhote", "velhice", "velhão", “ancião", dentre outros, mas se adota o "tratamento mais respeitoso": idoso (PEIXOTO, 2007, p. 78). De igual forma consta no Estatuto do Idoso, o artigo $1^{\circ}$, cujo objetivo dispõe regular os direitos assegurados às pessoas com idade igual ou superior a sessenta anos. (BRASIL, 2020).

Ademais, o critério etário ou cronológico, tomado para acolher e conceituar o Idoso, mesmo com críticas a esse respeito, é pouco preciso para definir a pessoa idosa. Segundo Agustini (2002, p. 24): “acaba sendo o mais utilizado quando existe a necessidade de delimitar a população a ser estudada, seja do ponto de vista epidemiológico ou administrativo ou para comparação de dados". De igual forma, Debert (1999, p. 76) aponta que "tratar das idades 
cronológicas é reconhecer que elas são um elemento fundamental na tarefa do Estado moderno", enquanto Peres (2011, p. 115) revela que "essa é a única forma de se atender ao interesse da maioria, uma vez que a análise pontual - caso a caso - inviabiliza o projeto de se conceder uma proteção especial, além de não dar segurança jurídica”.

Nessa linha, dois outros importantes Autores, elucidam uma importante conceitualização. Trata-se de Beauvoir (1990, p. 345) para quem "a velhice é o que acontece às pessoas que ficam velhas; impossível encerrar essa pluralidade de experiências num conceito, ou mesmo numa noção", e, também, Bobbio (1997, p.18), o qual pondera que "ao lado da velhice censitária ou cronológica e da velhice burocrática, existe também a velhice psicológica ou subjetiva”. Esses dois conceitos, fundamentais à matriz cronológica, conferem dinamicidade a uma condição repleta de complexidade.

Com relação ao critério cronológico do Idoso, a grosso modo, três modos chamam a atenção deste estudo, os marcos são 50, 60 e 65 anos, via de regra. Para a Organização Mundial de Saúde (OMS), em relação aos países desenvolvidos, aos 65 anos a pessoa é considerada Idosa. Para os países em desenvolvimento há variação neste critério, de forma que, no caso da África, aos 50 (cinquenta) anos a pessoa é considerada idosa (OMS, 2015). Já para os países em desenvolvimento, é considerada idosa pessoa com idade igual ou superior a 60 anos (ONU, 2015). Senão, veja-se conforme aponta a World Health Organization (WHO, 2020):

\begin{abstract}
A maioria dos países do mundo desenvolvido aceitou a idade cronológica de 65 anos como uma definição de 'idoso' ou pessoa idosa, mas, como muitos conceitos ocidentalizados, isso não se adapta bem à situação na África. Embora essa definição seja um tanto arbitrária, muitas vezes está associada à idade em que se pode começar a receber benefícios de pensão. No momento, não existe um critério numérico padrão das Nações Unidas, mas o ponto de corte acordado pela ONU é de mais de 60 anos para se referir à população mais velha ${ }^{15}$.
\end{abstract}

De acordo com os critérios da ONU, e nos moldes de conforme dispõe o Estatuto do Idoso, em relação ao Brasil, é considerada Idosa a pessoa com idade igual ou superior a 60 anos, o que se encontra corroborado com o Estatuto do Idoso.

Com o aumento do número de idosos no país, consequentemente se terá a necessidade de cuidados e atenção na área da saúde, tanto por intermédio do sistema público, quanto pelo sistema privado.

\footnotetext{
15 "Most developed world countries have accepted the chronological age of 65 years as a definition of 'elderly' or older person, but like many westernized concepts, this does not adapt well to the situation in Africa. While this definition is somewhat arbitrary, it is many times associated with the age at which one can begin to receive pension benefits. At the moment, there is no United Nations standard numerical criterion, but the UN agreed cutoff is 60+ years to refer to the older population." (Tradução livre) WORLD HEALTH ORGANIZATION. Proposed working definition of an older person in Africa for the MDS Project. Disponível em: who.int/healthinfo/survey/ageingdefnolder/en/. Acesso em: 20 abr. 2020.
} 
Em relação a perspectiva de participação e atuação do Idoso, nos termos conforme apontado no início deste estudo, o segundo aspecto diz respeito a uma matriz processual ou de gestão, a qual, conforme registra a ONU (2020), confere ao mundo o centro de uma transição do processo demográfico único e irreversível que irá resultar em mais populações Idosas em todos os lugares. O número de pessoas com 60 anos ou mais deve dobrar entre 2007 e 2050, e os números deverão mais que triplicar, até cerca de dois bilhões em 2050. Além do mais, na maioria dos países, o número de pessoas com mais de 80 anos deve quadruplicar até quase 400 milhões.

Em termos globais numéricos, o número de pessoas Idosas - com 60 ou mais - irá aumentar para 1,4 bilhão em 2030 até 2,1 bilhões em 2050, quando todas as regiões do mundo, com exceção da África, terão $1 \frac{1}{4}$ e até mais de sua população com 60 anos de idade ou mais, de forma que, no ano de 2100, o número de pessoas idosas pode alcançar 3,1 bilhões. (ONU, 2020).

As pessoas Idosas têm, paulatinamente, sido reconhecidas como contribuintes para o desenvolvimento, e suas habilidades para melhorar suas vidas e a das demais pessoas, incluindo as de suas sociedades necessitam receber políticas e programas por parte dos Estados. De igual forma, seus direitos necessitam de atenção e reconhecimento. Nesse viés, podem ser elencados, a independência, a participação, o cuidado, a autorrealização e a dignidade, para citar alguns desses exemplos. (ONU, 2020).

O terceiro aspecto refere a uma ideia básica, um ponto de partida de uma lista de capacidades que serão exigências centrais para uma vida com dignidade, conforme indicadas por Nussbaum (2013), cuja essencialidade reputa-se às questões de impedimento e deficiência. São, pois, modos de romper com essas questões. Mas, por razões práticas, “as capacidades são entendidas tanto como mutuamente assistentes, quanto todas de relevância central para a justiça social”. (NUSSBAUM, 2013, p. 91).

O enfoque dessas capacidades não detém o condão de traduzir ou de fornecer uma explicação completa, e sim de repensar algumas exigências fundantes e centrais a favor de uma vida com dignidade. São elas: $a$ vida, com o sentido de ter capacidade de viver até o fim de uma vida humana com duração normal, qual seja, não morrer prematuramente; saúde fisica, ter boa saúde; alimentação adequada; e dispor de um lugar adequado para viver; integridade física, ser capaz de movimentar de um lugar para outro e de estar protegido contra ataques da violência; imaginação e o pensamento, ser capaz de usar os sentidos, a imaginação, o pensamento e o raciocínio; emoções, de forma a manter relações afetivas com coisas e pessoas; razão prática, ser capaz de conferir uma concepção do bem; afiliação, ser capaz de viver voltado para os outros e de viver uma relação respeitosa com os animais, plantas e o mundo da natureza; lazer, ser 
capaz de brincar e de rir; e, por último, o controle sobre o próprio ambiente, cujo significado detém o sentido de participação política, proteção de liberdade de expressão e associação e ser capaz de ter direitos de propriedade. (NUSSBAUM, 2013, p. 91-92).

Trata-se, pois, de refletir em torno da dignidade humana e o que ela traduz, não obstante, essa lista pode concitar a um enfoque voltado aos Direitos, em especial os Direitos Humanos, o que é, sobremaneira, de absoluta pertinência aos Direitos do Idoso.

Logo, resta caracterizada a necessidade de se proteger, de se promover, e de se defender os Direitos do Idoso, tão mais em tempos de Pandemia, na perspectiva digna, fraterna e relacional. Dever este atribuído à família, à Sociedade e ao Estado, pois, conforme já explicado, a Pandemia instalada pela COVID-19 possui como marcador considerável: a saúde dos Idosos.

\section{A Fraternidade e os Objetivos Globais em tempos de Pandemia: o reconhecimento da agenda em prol do Idoso - por um novo e urgente modelo relacional}

Na contemporaneidade, o que constitui esse novo modelo inclusivo, com viés relacional, quando o tema é a categoria do Idoso?

As respostas ao presente questionamento comportam desde a categorização dos movimentos sociais, como a proposição que constitui amiúde um primeiro estágio de comportamento coletivo, cujos exemplos, perpassando a recepção dos mecanismos de participação voltados ao Idoso, usufruem de significativa importância no cenário atual.

Conforme visto anteriormente, na esfera das capacidades, foi visto que referidas aptidões, detém na dignidade, no Direito e, sobretudo, nos Direitos Humanos, a sua valiosa contribuição às perspectivas relacionais, quando voltadas ao Idoso, em sua melhor tradução de forma a que todos conheçam.

O ideal de participação, incluindo também o ideal democrático, pressupõe a participação nas Sociedades, o qual supõe igualmente a participação de cidadãos na corrente dos movimentos sociais. Não somente isto. Nessa linha, segundo Matiello (2018, p. 93) é preciso promover as mais variadas iniciativas, a fim de elaborar e difundir uma nova cultura jurídica assentada na relacionalidade, qual seja, uma nova dimensão "que evidencia a natureza relacional do ser humano, em um contexto mundial em que cada vez mais a relação interpessoal é negligenciada". (MATIELLO, 2018, p. 91-92).

A contemporaneidade está a exigir novos padrões de interação entre os agentes públicos e privados, cujo exemplo, os movimentos voltados à população Idosa, guarda relevância pelo 
simples fato de que o envelhecimento da população mundial requer o enfrentamento de seus próprios problemas, a proteção de medidas reivindicatórias e a promoção de pesquisas voltadas à questão, representativos desse novo modelo de agir, atualizado com o anseio de participação, inclusive dos órgãos internacionais.

A ONU preocupada com o envelhecimento populacional, conforme exposto neste estudo, atua em prol dos Direitos do Idoso há três décadas. Diante desse cenário, por certo a Fraternidade detém a condição de ser portadora dos elementos necessários ao contexto dos novos padrões de interação, incluindo a possibilidade de uma agenda nos planos internacional e nacional dirigida ao Idoso.

Por certo a opção detém como base, a indicação da Fraternidade utilizada como princípio, categoria, expectativa ou experiência, consoante indicado por Barraneche (2010, p. 18-20), tomada com os seguintes sentidos, respectivamente: a) em relação ao princípio, a expressão confere o sentido da base, origem, ou razão fundamental; b) por categoria a fraternidade detém a conotação de ciência; c) na qualidade de perspectiva a fraternidade se revela com a dimensão de um programa; e, d) quanto a experiência a fraternidade detém o condão de sua própria aplicação.

Com efeito, a partir da dinâmica da Fraternidade voltada para a sua própria vocação de convívio social, na qual o eu e os outros poderão dimensionar uma base que se cria e recria no outro e com os outros, com vistas a obtenção de uma base de participação e cooperação, que, segundo a matriz haberliana, "são fundamentais, nas esferas nacional-constitucional e na internacional" (VERONESE, 2015, p. 30).

A escolha é compatível, eis que a Fraternidade detém a base da participação e do comprometimento, sendo que os Objetivos Globais, sobretudo quando centrados nos Direitos e nas questões dos Idosos, requerem um sustentáculo voltado a tal dinâmica, o que é, por certo, tarefa que requer seja concluída, de forma a estabelecer, com base na Fraternidade, uma agenda resolutiva da participação social de forma que, daí decorra, um papel transformador nos padrões de interação, quanto ao alcance das metas dos Objetivos Globais, como os Objetivos de Desenvolvimento Sustentável (ODS), estabelecidos pela ONU.

Nesse sentido, o presente estudo expõe a Fraternidade como elemento fundamental para a disseminação e o alcance dos Objetivos Globais, tendo como cenário o contexto dos novos padrões de interação e a possibilidade de uma agenda nos planos internacional e nacional dirigida ao Idoso em tempos de Pandemia.

A tarefa se justifica, eis que, se de um lado, a Fraternidade tem como base a participação e o comprometimento, de outro, os Objetivos Globais requerem um sustentáculo 
voltado a tal dinâmica. Portanto, examinar essas duplas dimensões - Fraternidade e Objetivos Globais - aplicando-as às questões do Idoso em tempos de Pandemia, é por certo tarefa que requer seja concluída de forma a estabelecer, com base na Fraternidade, uma agenda resolutiva da participação social e de seu papel transformador nos padrões de interação no alcance das metas dos Objetivos Globais, estabelecidos pela ONU.

A ONU (2015) destaca: as pessoas tendem a valorizar e respeitar os idosos que amam ou conhecem e suas atitudes para com os outros na comunidade podem ser diferentes. Em muitas Sociedades, o Idoso é respeitado, porém, em outras menos e a marginalização pode ser estrutural; por exemplo, quanto à idade de aposentadoria ou informal, contra as pessoas mais velhas vistas como menos produtivas e menos valiosas para um potencial empregador. Essas atitudes são exemplo de "ageism"16 - estereótipos de discriminação contra indivíduos ou grupos por causa da sua idade.

O mesmo modo de agir que se tem com relação ao idoso que se ama ou conhece, deve ser direcionado a todos indistintamente, e dessa forma, nasce um novo modelo relacional: Fraterno.

Baggio afirma que a Fraternidade "non è utopia, ma strategia delle più efficaci" 17 . Nesse sentido, escreve Lubich (2013, p. 134) que "pode-se afirmar que a fraternidade universal não só não é uma utopia, um desejo belo e desejável, mas, no fundo, irrealizável; ela é antes uma realidade que, cada vez mais, vai ganhando terreno na história".

Há de ser visto que a fraternidade em sua dinâmica relacional, traz ínsita um "passo adiante", correspondente às necessidades do mundo atual e que só pode ser realizada segundo uma vida conduzida com liberdade e abertura comuns, a experimentar a arte do diálogo. (MATIELLO, 2018, p. 136).

Nussbaum pondera a importância de se fazer com que as pessoas se dêem conta do caráter injusto do trato da sociedade, sendo este um primeiro passo necessário para o progresso social (p. 328). De igual forma, Consoli considera que "o sentimento de egoísmo que impera nas relações sociais, mesmo as que se revestem das formalidades que justificam a qualidade de

\footnotetext{
${ }^{16}$ Conceito trazido por Richard Butler, no final de 1960 e adotado pela Comissão para o Desenvolvimento Social da ONU, durante a Segunda Assembleia Mundial sobre o Envelhecimento, realizada em Madrid em 2002, a qual assim definiu "meio pelo qual os direitos das pessoas idosas são negados ou violados. Estereótipos negativos e o denegrir das pessoas mais velhas podem ser traduzidos numa ausência de preocupação social para com os idosos, em risco de marginalização e na negação de igualdade de oportunidades, recursos e direitos" (VIEGAS; GOMES, 2007, p 29).

17 "Não é utopia, mas estratégia de eficácia" (Tradução livre). BAGGIO, Antonio Maria. La fraternitá: una nuova categoria nello spazio pubblico. In: VERONESE, Josiane Rose Petry; OLIVEIRA, Olga Maria B. Aguiar (org.). Direitos na pós-modernidade: a fraternidade em questão. Florianópolis: Fundação Boiteux, 2011. p. 16.
} 
'justas', deve ser afastado para que só então possa se falar em relações fraternas e por consequência justas". (2011, p. 174).

Também, escreve Cury (2011, p. 346) que a fraternidade pode excluir o egoísmo "que muitas vezes congela os relacionamentos, e passa a exigir dos cidadãos o dever de acompanhar o Estado e a comunidade".

A Declaração Universal dos Direitos Humanos, aprovada pela ONU em 1948, norma comum a ser observada, também trata da fraternidade em seu artigo $1^{\circ}$, nos seguintes termos: "Todos os seres humanos nascem livres e iguais em dignidade e direitos. São dotados de razão e consciência e devem agir em relação uns aos outros com espírito de fraternidade”.

Além desse importante documento versar sobre a Fraternidade, especialmente sobre o dever de todos de agir com espírito de Fraternidade, a Constituição da República Federativa do Brasil de 1988 (BRASIL, 1998), por seu turno, também expressa em seu Preâmbulo, como valor supremo construir uma: "sociedade fraterna". Nesse contexto, julgou o Supremo Tribunal Federal na Ação Direta de Inconstitucionalidade (ADI) n. 2.649. (BRASIL, 2008).

Para tanto, deve-se resgatar o novo modelo relacional: o Fraterno. Afinal, com prática de atitudes que respeitam, valorizam, protegem, promovem e defendem os Direitos do Idoso, especialmente daqueles expressos como Objetivos Globais, haverá a aplicação da solidariedade e da Justiça, consequentemente, chegar-se-á a tão almejada paz. Mais, a alcançar uma dinâmica de confiança, de diálogo e de troca de dádivas em que os participantes são os atores, as gerações a vivenciar o diálogo e propor a relacionalidade permeada pela soaciabilidade.

\section{Considerações finais}

A Fraternidade é compromisso de todos: Família, Sociedade e Estado, os quais têm o papel de proteger, de promover e de defender os Direitos do Idoso. E, segue relevante introduzir a Fraternidade quando associada aos Objetivos Globais, destacadamente em tempos de Pandemia, obtendo-se Direitos na esfera nacional e internacional, pertinentes ao Idoso, com qualidade o bastante para submetê-los a um padrão de eficácia.

Das preocupações refletidas pela ONU, conclui-se que não basta a simples solidariedade humana, mas sim o resgate do "espírito fraterno", expresso no artigo $1^{\circ}$ da Declaração Universal dos Direitos Humanos, que recomenda a todos dispensar ao Idoso o mesmo tratamento relacional dispensado àquele que se ama ou ao conhecido. 
De igual forma, também, espera-se uma cidadania efetiva, cuja tônica do reconhecimento da diversidade humana privilegie a promoção, a proteção e a defesa do Idoso, com instituições e organismos que potencializem condições para a existência humana, sem referência à oposição que pode ser antagônica, entre autoridade, autonomia e participação, cujo padrão seja de interação entre os agentes públicos e privados.

Como visto, a Fraternidade carrega em si a tarefa de valorar a atuação dos Direitos de proteção, promoção e defesa do Idoso, quer nas questões ocorrentes no Estado Constitucional, quer no espaço doméstico, quer na seara internacional, e, assim, conferir suporte a questão problematizadora do presente - esse novo modelo de agir na contemporaneidade a se ocupar da categoria do Idoso, com ênfase para seus Direitos, em especial os relativos à Saúde, direcionados a todos indistintamente.

Dessa forma, nasce uma nova capacidade: um bem relacional, que emana do agir em benefício de outrem, ou seja, que desponta do socorro mútuo prestado entre as pessoas, e que se coloca ao lado daquela outra forma baseada na intervenção direta do Estado - inclusive dos Poderes Públicos - em socorro das vulnerabilidades - o que estes tempos da COVID-19 são reveladores, na medida em que afetam toda a sociedade - doméstica e internacional. Aliás, os países, incluindo os organismos internacionais, como é o caso da ONU, todos, enquanto agentes de Fraternidade, terão a importante missão de, nas relações mútuas entre os povos, entre os cidadãos, entre os que se estabelecem na sociedade, de velar pelo reconhecimento da própria Fraternidade - sem a qual, não se pode esperar uma agenda de proteção, de promoção e de defesa dos Idosos, sobretudo, quando voltada aos Direitos relacionados à Seguridade Social, com destaque à Saúde.

\section{REFERÊNCIAS}

AGUSTINI, Carlos Fernando. A velhice na Constituição brasileira de 1988 como direito fundamental. 2002. Dissertação (Mestrado em Direito) - Universidade Federal de Santa Catarina, Florianópolis.

BAGGIO, Antonio Maria. La fraternitá: una nuova categoria nello spazio pubblico. In: VERONESE, Josiane Rose Petry; OLIVEIRA, Olga Maria B. Aguiar (org.). Direitos na pósmodernidade: a fraternidade em questão. Florianópolis: Fundação Boiteux, 2011, p. 9-18.

BARRANECHE, Osvaldo. Estudios recientes sobre fraternidad: de la enunciación como principio a la consolidación como perspectiva. ${ }^{\mathrm{a}}$. Ed. Buenos Aires: Ciudad Nueva, 2010.

BEAUVOIR, Simone de. A velhice. Tradução de Maria Helena Franco Monteiro. Rio de Janeiro: Nova Fronteira, 1990. 711 p. 
BOBBIO, Norberto. O tempo da memória: de senectute e outros escritos autobiográficos. Tradução de Daniela Versiani. Rio de Janeiro: Campus, 1997. 205 p.

BRASIL. Constituição da República Federativa do Brasil de 1988. Disponível em: www.planalto.gov.br/ccivil_03/constituicao/constituicaocompilado.htm. Acesso em 28 abr. 2020.

BRASIL. Fundação Oswaldo Cruz. Covid-19: que vírus é esse? Disponível em: portal.fiocruz.br/noticia/covid-19-que-virus-e-esse. Acesso em: 07 jun. 2020.

BRASIL. Lei n. 10.741, de $1^{\circ}$ de outubro de 2003. Dispõe sobre Estatuto do Idoso e dá outras providências. Disponível em: planalto.gov.br/ccivil_03/leis/2003/110.741.htm. Acesso em: 28 abr. 2020 .

BRASIL. Supremo Tribunal Federal. ADI 2649, Relatora Min. Cármen Lúcia, Tribunal Pleno, julgado em 08.05.2008, publicado em 17.10.2008. Disponível em:

redir.stf.jus.br/paginadorpub/paginador.jsp?docTP=AC\&docID=555517. Acesso em: 29 abr. 2020 .

CONSOLI, Anelícia Verônica Bombana. Direito e fraternidade: formula para o bem comum. In: Direitos na pós-modernidade: a fraternidade em questão. VERONESE, Josiane Rose Petry; OLIVEIRA, Olga Maria B. Aguiar (org.). Florianópolis: Fundação Boiteux, 2011, p. 163-176.

CURY, Munir. Direito e fraternidade na construção da justiça. In: VERONESE, Josiane Rose Petry; OLIVEIRA, Olga Maria B. Aguiar (org.). Direitos na pós-modernidade: a fraternidade em questão. Florianópolis: Fundação Boiteux, 2011, p. 325-352

DEBERT, Guita Grin. Velhice e o curso da vida pós-moderno. In: Revista USP, São Paulo, n. 42, p. 70-83, junho/agosto, 1999. Disponível em: usp.br/revistausp/42/06-guitagrin.pdf. Acesso em: 26 jan. 2015.

INTERNATIONAL SOCIAL SECURITY ASSOCIATION. Megatrends and social security: demographic changes. Geneva, 2017. Disponível em: issa.int/en/details?uuid=1438fdf2-cd994b0a-bb13-8913b829db1d. Acesso em 22 jan. 2019. p. iv.

LUBICH, Chiara. O amor mútuo. Tradução Irami B. Silva. Vargem Grande Paulista: Cidade Nova, 2013, 143 p.

MATIELLO, Suzana T. Chiara Lubich: O Radicalismo do Amor para uma Ética do Encontro. Tradução Klaus Brüschke. São Paulo: Cidade Nova, 2018.

NAÇÕES UNIDAS BRASIL. A ONU e as pessoas idosas. Disponível em: //nacoesunidas.org/acao/pessoas-idosas/. Acesso em: 7 jun. 2020.

NAÇÕES UNIDAS BRASIL. Conheça os novos 17 Objetivos de Desenvolvimento Sustentável da ONU. Disponível em: nacoesunidas.org/conheca-os-novos-17-objetivos-de-desenvolvimentosustentavel-da-onu/. Acesso em: 28 jun. 2020.

NOVAIS, Jorge Reis. Direitos Sociais - Teoria jurídica dos direitos sociais enquanto direitos fundamentais. 2 ed. Lisboa: AAFDL, 2017. 
NUSSBAUM, Martha C. Fronteiras da Justiça: Deficiência, Nacionalidade, Pertencimento à Espécie. Tradução Suzana de Castro e Malu Rangel. São Paulo: Wmfmartinsfontes, 2013.

NUSSBAUM, Martha C. La Ira y el Perdón: resentimento, generosidad, justicia. Traducción Victor Altamirano. México: FCE, 2018.

ORGANIZAÇÃO MUNDIAL DA SAÚDE. Datos interesantes acerca del envejecimiento. Disponível em: who.int/ageing/about/facts/es/. Acesso em: 18 jan. 2015.

ORGANIZAÇÃO MUNDIAL DA SAÚDE. Organização Mundial da Saúde. Definition of an older or elderly person. Disponível em: who.int/healthinfo/survey/ageingdefnolder/en/. Acesso em: 18 jan. 2015

ORGANIZAÇÃO MUNDIAL DA SAÚDE. Envejecimiento y ciclo de vida. Disponível em: who.int/ageing/about/ageing_life_course/es/. Acesso em: 18 jan. 2015.

ORGANIZAÇÃO DAS NAÇÕES UNIDAS. A ONU essencial. Disponível em: https://www.un.org/en/essential-un/. Acesso em: 29 jun.2020.

ORGANIZAÇÃO DAS NAÇÕES UNIDAS. A ONU e as pessoas idosas. Disponível em: https://nacoesunidas.org/acao/pessoas-idosas/. Acesso em: 29 jun.2020.

ORGANIZAÇÃO DAS NAÇÕES UNIDAS. Declaração Universal dos Direitos Humanos. Disponível em: dudh.org.br/wp-content/uploads/2014/12/dudh.pdf. Acesso em 26 fev. 2015.

ORGANIZAÇÃO DAS NAÇÕES UNIDAS. Resolução n. 37/51, de 3 de dezembro de 1982. Plano de Ação Internacional de Viena Sobre o Envelhecimento. Disponível em: ufrgs.br/epsico/publicas/humanizacao/prologo.html. Acesso em: 6 mar. 2015.

ORGANIZAÇÃO DAS NAÇÕES UNIDAS. Resolução n. 46/91. Princípios das Nações Unidas para as pessoas idosas. Disponível em: un.org/documents/ga/res/46/a46r091.htm. Acesso em: 18 jan. 2015.

ORGANIZAÇÃO DAS NAÇÕES UNIDAS. A ONU e as pessoas idosas. Disponível em: nacoesunidas.org/acao/pessoas-idosas/. Acesso em: 18 jan. 2015.

ORGANIZAÇÃO DAS NAÇÕES UNIDAS. Are you ready? What you need to know about ageing. Disponível em: who.int/world-health-day/2012/toolkit/background/en/index3.html. Acesso em: 28 jan. 2015.

ORGANIZAÇÃO DAS NAÇÕES UNIDAS. ONU pede saúde adequada a idosos em todo o mundo. Disponível em: nacoesunidas.org/onu-pede-saude-adequada-a-idosos-em-todo-o-mundo/. Acesso em: 18 jan. 2015.

ORGANIZAÇÃO DAS NAÇÕES UNIDAS. Programa das Nações Unidas para o Desenvolvimento. Declaração do Milênio. Disponível em: pnud.org.br/Docs/declaracao_do_milenio.pdf. Acesso em: 6 mar. 2015.

ORGANIZAÇÃO DAS NAÇÕES UNIDAS. World Population Ageing 2013. Disponível em: un.org/esa/socdev/documents/ageing/Data/WorldPopulationAgeingReport2013.pdf. Acesso em: 28 jan. 2015. 
PEIXOTO, Clarice. Entre o estigma e a compaixão e os termos classificatórios: velho, velhote, idoso, terceira idade... In: Velhice ou terceira idade? Estudos antropológicos sobre identidade, memória e política. Organizado por Myriam Moraes Lins de Barros. Rio de Janeiro: Editora FGV, 2007. $236 \mathrm{p}$.

PERES, Ana Paula Ariston Barion. Proteção aos idosos. Curitiba: Juruá, 2011. 128 p.

UNITED NATIONS. About the Sustainable Development Goals. Disponível em: un.org/sustainabledevelopment/sustainable-development-goals/. Acesso em: 7 jun. 2020.

UNITED STATES OF AMERICA. Department of Health and Human Services. Centers for Disease Control and Prevention. Older Adults. Page last reviewed: April 30, 2020. Disponível em: cdc.gov/coronavirus/2019-ncov/need-extra-precautions/older-adults.html. Acesso em: 07 jun. 2020.

UNITED STATES OF AMERICA. Department of Health and Human Services. Centers for Disease Control and Prevention. Older Adults. Page last reviewed: June 25, 2020. Disponível em: cdc.gov/coronavirus/2019-ncov/need-extra-precautions/older-adults.html. Acesso em: 28 jun. 2020 .

UNITED STATES OF AMERICA. Department of Health and Human Services. Centers for Disease Control and Prevention. Cases in the U.S. Disponível em: cdc.gov/coronavirus/2019ncov/cases-updates/cases-in-us.html. Acesso em: 28 jun. 2020.

UVO BODNAR, Roberta Terezinha; PILATI, José Isaac. O direito do idoso à saúde: preceitos legais internacionais e nacionais à luz do direito fraterno. In: Objetivos e metas desenvolvimento do milênio da ONU [Recurso eletrônico on-line] organização CONPEDI/UFS; Coordenadores: Flavia Piva Almeida Leite, Janaína Rigo Santin, Jefferson Aparecido Dias. Florianópolis: CONPEDI, 2015. p. 130. Disponível em: conpedi.danilolr.info/publicacoes/c178h0tg/091ud5at/iZ6PFY1P010G6CS5.pdf. Acesso em: 04 maio 2020.

VERONESE, Eduardo Rafael Petry. Um conceito de fraternidade para o Direito. Rio de Janeiro, 2015. Editora Lumen Juris, 2015.

VIEGAS, Suzana de Matos; GOMES, Catarina Antunes. A identidade na velhice. Lisboa: AMBAR, 2007. 138 p.

WORLD HEALTH ORGANIZATION. Ageing and health. 5 feb. 2018. Disponível em: who.int/news-room/fact-sheets/detail/ageing-and-health. Acesso em: 29 abr. 2020. 